\title{
CALAJOULE: An Italian Research to Lessen Joule Power Losses in Overhead Lines by Means of Innovative Conductors
}

\author{
Roberto Benato ${ }^{1, * \mathbb{D}}$, Roberto Caldon ${ }^{1}$, Antonio Chiarelli ${ }^{1}$, Massimiliano Coppo ${ }^{1}$, \\ Claudio Garescì ${ }^{2}$, Sebastian Dambone Sessa ${ }^{1} \mathbb{1}$, Debora Mimo ${ }^{3}$, Michele Modesti ${ }^{1}{ }^{1}$, \\ Luca Mora ${ }^{3}$ and Francesca Piovesan ${ }^{1}$ \\ 1 Department of Industrial Engineering, University of Padova, 35131 Padova, Italy \\ 2 Nuova Elettromeccanica Sud (NES) s.p.a. Campo Calabro, 89052 Reggio Calabria, Italy \\ 3 De Angeli Prodotti S.r.l. Bagnoli di Sopra, 35023 Padova, Italy \\ * Correspondence: roberto.benato@unipd.it; Tel.: +39-049-827-7532
}

Received: 15 July 2019; Accepted: 6 August 2019; Published: 13 August 2019 updates

\begin{abstract}
The ongoing evolution of the power system to implement climate action policies is resulting in a continuous increase in the penetration of renewables and the necessity of strengthening the transmission grid to optimize the usage of those sources and contain operation costs. Reinforcing the transmission lines or building new ones is a process that is made difficult due to authorization issues related with environmental and public acceptance concerns. Developing innovative conductors for overhead lines with enhanced performances with respect to the traditional ones would bring benefits in terms of energy efficiency increases in transmission and distribution grids without requiring the substitution of the existing towers. The project CALAJOULE (the genesis of the acronym comes from the union of the Italian verb "calare"-to decrease-to the third person singular, namely "cala" i.e., decreases, and of Joule, obvious reference to the active losses), cofinanced by the Italian Ministry of Economic Development in the framework of the "Ricerca di Sistema" program, aims at proposing innovative solutions for overhead line conductors for the containment of Joule power losses. In this paper, starting from the state-of-the-art of the currently adopted conductors, the main innovative solutions resulting from the project are presented and compared with the traditional ones to evaluate the achievable reduction in Joule losses.
\end{abstract}

Keywords: innovative conductors; overhead lines; power losses reduction

\section{Introduction}

In recent decades, the growth and economic development of some countries has resulted in a stimulus, and consequently an increase in consumption; among these is the increase in the demand for electricity. More recently, the climate action plans worldwide are demanding for an evolution of the electricity sector, in order to contain the emissions of greenhouse gas (GHG), improve the energy efficiency and increase the share of renewables in the electricity production. At the European level, the objectives set for 2020 are on the way to being fulfilled, with a GHG reduction of $22.4 \%$ compared to 1990 levels, along with $17 \%$ of final energy usage being covered by renewable sources [1]. With the release of the "clean energy for all Europeans" package in 2016, the EU parliament defined new objectives in the climate and energy framework for the period 2021 to 2030, which aims to continue the transition started in the previous period [2]. The introduction of the new objectives in energy efficiency improvement and renewables penetration is now leading to a revision of the network code and in the reform of the electricity markets [3], pursuing a better usage of electricity and higher 
flexibility. The above-mentioned climate action policies are resulting in an evolution of the generation park, with the gradual substitution of traditional fossil-fuelled power plants with a high number of smaller generators, the majority of which are connected to the distribution network. To accompany this change, it is of utmost importance to have a power system infrastructure capable of hosting the geographically displaced generation and the sudden changes in the power flows, containing the formation of bottlenecks, and improving the energy efficiency of the whole system. Along with innovative network management techniques [4], aiming at exploiting the presence of distributed generators and their participation to the ancillary services market [5], it will be necessary to upgrade the infrastructure of the electricity system as increasing shares of electricity production will shift from large power plants to small generators. As it is well known, active losses in electricity systems vary considerably depending on the voltage level. Typically, active losses ranging from $2 \%$ to $10 \%$ can be assumed, passing from transmission networks (high and extra-high voltage levels, HV and EHV, respectively) to distribution networks (medium and low voltage levels, MV and LV, respectively) [6-9]. For overhead lines (OHLs), the different Joule losses values are due to the $r / x$ ratios (ratio between the resistance $r$ and the reactance $x$ of the positive sequence impedance) of the transmission lines being much lower than those of the distribution networks. The reduction of Joule losses in the power system, both at transmission and distribution levels, therefore, plays a key role in increasing energy efficiency, with obvious advantages for the power system both in economic terms and in terms of reducing carbon dioxide emission into the atmosphere. This framework is extremely large, given the large extension of the power supply system and the different peculiarities of the EHV-HV and MV-LV networks. The typical Italian levels of the EHV-HV network are 380-220-150-132 kV, always with neutral solidly connected to earth. The MV network is typically operating at $20 \mathrm{kV}$ with neutral grounded through Petersen's resonant coil [10], although some parts operate at $60 \mathrm{kV}$ with neutral isolated [11], while the LV network $(400 \mathrm{~V})$ operates with neutral solidly grounded in the secondary substation.

Improving the power system capacity leads to either the construction of new power lines or the reinforcement of the existing ones. On the one hand, building new Overhead lines (OHLs) is a difficult process that leads to issues related with the regulatory process due to environmental and public acceptance concerns. On the other hand, substituting the currently installed standard conductors with others having a larger cross-section may cause an overall weight increase, resulting in the necessity of adapting the towers, dramatically increasing the investment costs.

The project CALAJOULE, cofinanced by the Italian Ministry of Economic Development in the framework of the "Ricerca di Sistema" program, aims at proposing innovative conductor prototypes for overhead lines for the containment of Joule power losses. This paper aims at disseminating all the main findings and conclusions of the CALAJOULE project, whereas some preliminary results had already been presented in some previously published papers $[12,13]$.

The main difference with respect to other literature contributions regarding innovative overhead conductors is that the developed solutions have been ideated not to increase current ratings and power flows but to lessen the Joule power losses. The positive economic and environmental impacts have been evaluated quantitatively for paradigmatic overhead lines. In this paper, after an overview of the state-of-the-art in currently adopted OHL conductors for the Italian transmission and distribution networks, two innovative conductor prototypes are proposed, according to the specific needs of the Italian distribution and transmission electric grids. For the novel conductor proposed for transmission and subtransmission grids, an experimental research on the core-coating material has been developed and presented in this paper for the first time in technical literature. Moreover, a procedure for the evaluation of the impact of substituting the traditional conductors with the proposed new ones is fully developed and presented, showing the potential results in containment of Joule power losses, in cost savings and in $\mathrm{CO}_{2}$ emission avoidance. Consequently, such approach allows quantitatively evaluating the positive economic and environmental impacts for paradigmatic overhead lines. In order to perform these above-mentioned evaluations of the whole benefit deriving from less power and energy losses, the research group has benefitted from some analytical tools created and invented by the Electric 
Energy Transmission Laboratory of the Padova Power Systems Group. In particular, the Ossanna's formulation has been extensively applied to a stepwise duration curve forecasting the power flows of a given overhead line [14-16]. The CALAJOULE researchers have also benefitted from a long experience in the transmission and distribution electric grids witnessed by several papers [17-21]. This topic is well covered in technical literature also in international working groups and standards [22-28].

\section{Current Solutions for Overhead Lines Conductors}

This section presents an overview of the presently installed conductors for OHLs and some of the commercially available solutions. Since the scope of this project is to develop new conductors for the Italian context, the overview refers to Italian OHLs, both in the transmission (HV and EHV) and distribution (MV and LV) grids. However, a similar distribution can be assumed for other contexts given the existing standardization in the conductor typologies.

\subsection{State-of-the-Art of OHL Conductors}

At the time of building of most of the currently existing OHLs the electrical companies were still vertically integrated, meaning that all the entire electricity chain (from production to final delivery) was owned by the same company. This is one of the reasons why the conductors adopted in power system wiring are standardized, and typically grouped in few types, depending on the voltage level. Due to its good mechanical performances, the most used type is aluminium conductor steel reinforced (ACSR), whereas aluminium alloys (e.g., Aldrey, generally known as AAAC: All Aluminium Alloy Conductor) and copper (especially in older LV lines) may be found in the cases where the mechanical stresses are lighter, so the priority is on increasing the overall conductibility.

In Table 1, the conductors types mostly used in the Italian transmission grid are summarized with reference to the respective lengths. As it can be seen from Table 1, at EHV and HV levels (380 and $220 \mathrm{kV}$ ), over $95 \%$ of the lines are equipped with ACSR conductors due to the high mechanical performances required as a result of long spans and high linear weight due to a large cross-section. Furthermore, given the high capacity needed in these power lines, along with the necessity of reducing the corona effects, most of the OHLs are equipped with bundles of two or three conductors (about $50 \%$ ), as can be seen in Table 2, reporting the ACSR conductors divided by the main cross-sections installed. Although a detailed analysis of all the HV Italian power system was not possible due to unavailability of data, the main conductor types adopted in the $150-132 \mathrm{kV}$ system are still ACSR, but with the cross-section more likely to be about $308 \mathrm{~mm}^{2}$.

In distribution networks, as shown in Table 3, although ACSR conductors are still present in a significant share (about 16\%), most of the OHLs are equipped with copper conductors, especially at LV level. A detailed distribution of OHLs conductor types is reported in Table 4, in which it can be seen that a significant share of the copper conductors has a cross-section below $25 \mathrm{~mm}^{2}$ (about $50 \%$ of the total extension, mostly LV).

Table 1. Italian extra-high voltage level (EHV) and high voltage level (HV) transmission network extension divided by main wire types in $(\mathrm{km})$ and in $(\%)$ respect to the total.

\begin{tabular}{ccccccc}
\hline & \multicolumn{2}{c}{ ACSR } & \multicolumn{2}{c}{ CU } & \multicolumn{2}{c}{ AAAC } \\
\hline North & 9956 & $(100.0 \%)$ & 0 & $(0.0 \%)$ & 0 & $(0.0 \%)$ \\
Central & 4821 & $(88.2 \%)$ & 212 & $(3.9 \%)$ & 435 & $(8.0 \%)$ \\
South & 6198 & $(94.7 \%)$ & 348 & $(5.3 \%)$ & 32 & $(0.5 \%)$ \\
Total & 20,975 & $(95.5 \%)$ & 560 & $(2.5 \%)$ & 467 & $(2.1 \%)$ \\
\hline
\end{tabular}


Table 2. Detail of the Italian EHV Transmission network extension divided by cross-sections $\left(\mathrm{mm}^{2}\right)$ and number of subconductors per phase of aluminium conductor steel reinforced (ACSR) conductors in $(\mathrm{km})$ and in $(\%)$.

\begin{tabular}{|c|c|c|c|c|c|c|c|c|c|c|c|}
\hline $\begin{array}{c}\text { Whole } \\
\text { Cross-Section } \\
\text { in }\left(\mathrm{mm}^{2}\right)\end{array}$ & 308 & 4 & & 509 & & 585 & & 708 & 755 & 1865 & \multirow{2}{*}{ Total } \\
\hline $\begin{array}{l}\text { Number of } \\
\text { Subconductors } \\
\text { per Phase }\end{array}$ & 1 & 1 & 2 & 1 & 1 & 2 & 3 & 1 & 1 & 1 & \\
\hline North & $\begin{array}{c}319 \\
1.54 \%\end{array}$ & $\begin{array}{c}3147 \\
15.20 \%\end{array}$ & $\begin{array}{c}483 \\
2.33 \%\end{array}$ & $\begin{array}{c}957 \\
4.62 \%\end{array}$ & $\begin{array}{c}1000 \\
4.83 \%\end{array}$ & $\begin{array}{c}163 \\
0.78 \%\end{array}$ & $\begin{array}{c}2843 \\
13.73 \%\end{array}$ & $\begin{array}{c}205 \\
0.99 \%\end{array}$ & $\begin{array}{c}0 \\
0.00 \%\end{array}$ & $\begin{array}{c}838 \\
4.05 \%\end{array}$ & $\begin{array}{c}9956 \\
48.07 \%\end{array}$ \\
\hline Central & $\begin{array}{c}124 \\
0.60 \%\end{array}$ & $\begin{array}{c}433 \\
2.09 \%\end{array}$ & $\begin{array}{c}0 \\
0.00 \%\end{array}$ & $\begin{array}{c}435 \\
2.10 \%\end{array}$ & $\begin{array}{c}93 \\
0.45 \%\end{array}$ & $\begin{array}{c}556 \\
2.68 \%\end{array}$ & $\begin{array}{c}2987 \\
14.42 \%\end{array}$ & $\begin{array}{c}0 \\
0.00 \%\end{array}$ & $\begin{array}{c}0 \\
0.00 \%\end{array}$ & $\begin{array}{c}153 \\
0.74 \%\end{array}$ & $\begin{array}{c}4780 \\
23.08 \%\end{array}$ \\
\hline South & $\begin{array}{c}0 \\
0.00 \%\end{array}$ & $\begin{array}{c}11 \\
0.05 \%\end{array}$ & $\begin{array}{c}0 \\
0.00 \%\end{array}$ & $\begin{array}{c}620 \\
2.99 \%\end{array}$ & $\begin{array}{c}96 \\
0.46 \%\end{array}$ & $\begin{array}{c}311 \\
1.50 \%\end{array}$ & $\begin{array}{c}2432 \\
11.74 \%\end{array}$ & $\begin{array}{c}6 \\
0.03 \%\end{array}$ & $\begin{array}{c}0 \\
0.00 \%\end{array}$ & $\begin{array}{c}0 \\
0.00 \%\end{array}$ & $\begin{array}{c}3475 \\
16.78 \%\end{array}$ \\
\hline Islands & $\begin{array}{c}0 \\
0.00 \%\end{array}$ & $\begin{array}{c}0 \\
0.00 \%\end{array}$ & $\begin{array}{c}0 \\
0.00 \%\end{array}$ & $\begin{array}{c}0 \\
0.00 \%\end{array}$ & $\begin{array}{c}1480 \\
7.14 \%\end{array}$ & $\begin{array}{c}177 \\
0.86 \%\end{array}$ & $\begin{array}{c}526 \\
2.54 \%\end{array}$ & $\begin{array}{c}0 \\
0.00 \%\end{array}$ & $\begin{array}{c}315 \\
1.52 \%\end{array}$ & $\begin{array}{c}0 \\
0.00 \%\end{array}$ & $\begin{array}{c}2498 \\
12.06 \%\end{array}$ \\
\hline Network total & $\begin{array}{c}444 \\
2.14 \%\end{array}$ & $\begin{array}{c}3591 \\
17.34 \%\end{array}$ & $\begin{array}{c}483 \\
2.33 \%\end{array}$ & $\begin{array}{c}2012 \\
9.72 \%\end{array}$ & $\begin{array}{c}2668 \\
12.88 \%\end{array}$ & $\begin{array}{r}1207 \\
5.83 \%\end{array}$ & $\begin{array}{c}8788 \\
42.43 \%\end{array}$ & $\begin{array}{c}211 \\
1.02 \%\end{array}$ & $\begin{array}{c}315 \\
1.52 \%\end{array}$ & $\begin{array}{c}991 \\
4.78 \%\end{array}$ & $\begin{array}{l}20,709 \\
100.00 \%\end{array}$ \\
\hline
\end{tabular}

Table 3. Italian distribution network (MV and LV) main wire types extension in $(\mathrm{km})$ and $(\%)$ respective to the total lines extension.

\begin{tabular}{ccccccccc}
\hline & \multicolumn{2}{c}{ ACSR } & \multicolumn{2}{c}{ AAC } & \multicolumn{2}{c}{ CU } & \multicolumn{2}{c}{ AAAC } \\
\hline North & 8880 & $(19.5 \%)$ & 356 & $(0.8 \%)$ & 32,786 & $(72.1 \%)$ & 2603 & $(5.7 \%)$ \\
Central & 4788 & $(7.3 \%)$ & 318 & $(0.5 \%)$ & 59,969 & $(91.9 \%)$ & 38 & $(0.1 \%)$ \\
South & 16,420 & $(20.2 \%)$ & 1331 & $(1.6 \%)$ & 56,038 & $(69.0 \%)$ & 6420 & $(7.9 \%)$ \\
TOTAL & 30,090 & $(15.7 \%)$ & 2005 & $(1.0 \%)$ & 148,789 & $(77.5 \%)$ & 9062 & $(4.7 \%)$ \\
\hline
\end{tabular}

Table 4. Detail of the distribution network (MV and LV) main wire types extension in $(\mathrm{km})$ and in $(\%)$ respective to the total extension.

\begin{tabular}{|c|c|c|c|c|c|c|c|c|c|c|c|c|c|c|}
\hline & & ACSR & & & AAC & & & $\mathrm{C}$ & & & & AAAC & & TOT \\
\hline $\begin{array}{l}\text { Cross } \\
\text { Section } \\
\left(\mathrm{mm}^{2}\right)\end{array}$ & $<100$ & $\begin{array}{l}\geq 100 \\
<150\end{array}$ & $\geq 150$ & $\leq 25$ & $\begin{array}{l}>25 \\
\leq 35\end{array}$ & $\geq 35$ & $\leq 16$ & $\begin{array}{l}>16 \\
\leq 25\end{array}$ & $\begin{array}{l}>25 \\
\leq 35\end{array}$ & $>35$ & $\leq 35$ & $\begin{array}{l}>35 \\
\leq 70\end{array}$ & $>70$ & - \\
\hline North & $\begin{array}{c}305 \\
0.16 \%\end{array}$ & $\begin{array}{c}264 \\
0.14 \%\end{array}$ & $\begin{array}{c}8311 \\
4.33 \%\end{array}$ & $\begin{array}{c}7 \\
0.00 \%\end{array}$ & $\begin{array}{l}109 \\
0.06 \%\end{array}$ & $\begin{array}{c}240 \\
0.13 \%\end{array}$ & $\begin{array}{c}4249 \\
2.21 \%\end{array}$ & $\begin{array}{l}14,364 \\
7.49 \%\end{array}$ & $\begin{array}{c}4450 \\
2.32 \%\end{array}$ & $\begin{array}{c}9723 \\
5.07 \%\end{array}$ & $\begin{array}{c}1322 \\
0.69 \%\end{array}$ & $\begin{array}{c}1077 \\
0.56 \%\end{array}$ & $\begin{array}{l}204 \\
0.11 \%\end{array}$ & $\begin{array}{l}45,480 \\
23.70 \%\end{array}$ \\
\hline Central & $\begin{array}{c}271 \\
0.14 \%\end{array}$ & $\begin{array}{c}213 \\
0.11 \%\end{array}$ & $\begin{array}{c}4304 \\
2.24 \%\end{array}$ & $\begin{array}{c}26 \\
0.01 \%\end{array}$ & $\begin{array}{c}43 \\
0.02 \%\end{array}$ & $\begin{array}{c}249 \\
0.13 \%\end{array}$ & $\begin{array}{l}15,424 \\
8.04 \%\end{array}$ & $\begin{array}{l}18,323 \\
9.55 \%\end{array}$ & $\begin{array}{l}18,774 \\
9.78 \%\end{array}$ & $\begin{array}{c}7448 \\
3.88 \%\end{array}$ & $\begin{array}{c}10 \\
0.01 \%\end{array}$ & $\begin{array}{c}7 \\
0.00 \%\end{array}$ & $\begin{array}{c}21 \\
0.01 \%\end{array}$ & $\begin{array}{l}65,236 \\
34.00 \%\end{array}$ \\
\hline South & $\begin{array}{c}420 \\
0.22 \%\end{array}$ & $\begin{array}{c}2542 \\
1.32 \%\end{array}$ & $\begin{array}{c}5504 \\
2.87 \%\end{array}$ & $\begin{array}{c}86 \\
0.04 \%\end{array}$ & $\begin{array}{l}259 \\
0.13 \%\end{array}$ & $\begin{array}{c}491 \\
0.26 \%\end{array}$ & $\begin{array}{l}12,656 \\
6.60 \%\end{array}$ & $\begin{array}{l}12,489 \\
6.51 \%\end{array}$ & $\begin{array}{c}5263 \\
2.74 \%\end{array}$ & $\begin{array}{c}487 \\
0.25 \%\end{array}$ & $\begin{array}{c}3179 \\
1.66 \%\end{array}$ & $\begin{array}{c}1458 \\
0.76 \%\end{array}$ & $\begin{array}{c}55 \\
0.03 \%\end{array}$ & $\begin{array}{l}45,365 \\
23.64 \%\end{array}$ \\
\hline Islands & $\begin{array}{c}273 \\
0.14 \%\end{array}$ & $\begin{array}{c}342 \\
0.18 \%\end{array}$ & $\begin{array}{c}7339 \\
3.82 \%\end{array}$ & $\begin{array}{c}1 \\
0.00 \%\end{array}$ & $\begin{array}{l}172 \\
0.09 \%\end{array}$ & $\begin{array}{c}322 \\
0.17 \%\end{array}$ & $\begin{array}{c}5833 \\
3.04 \%\end{array}$ & $\begin{array}{l}12,347 \\
6.43 \%\end{array}$ & $\begin{array}{c}4935 \\
2.57 \%\end{array}$ & $\begin{array}{c}2028 \\
1.06 \%\end{array}$ & $\begin{array}{c}1554 \\
0.81 \%\end{array}$ & $\begin{array}{c}161 \\
0.08 \%\end{array}$ & $\begin{array}{c}13 \\
0.01 \%\end{array}$ & $\begin{array}{l}35,809 \\
18.66 \%\end{array}$ \\
\hline $\begin{array}{l}\text { Network } \\
\text { total }\end{array}$ & $\begin{array}{c}1269 \\
0.66 \%\end{array}$ & $\begin{array}{c}3361 \\
1.75 \%\end{array}$ & $\begin{array}{l}25,458 \\
13.27 \%\end{array}$ & $\begin{array}{c}120 \\
0.06 \%\end{array}$ & $\begin{array}{l}583 \\
0.30 \%\end{array}$ & $\begin{array}{c}1302 \\
0.68 \%\end{array}$ & $\begin{array}{l}38,162 \\
19.89 \%\end{array}$ & $\begin{array}{l}57,523 \\
29.98 \%\end{array}$ & $\begin{array}{l}33,422 \\
17.42 \%\end{array}$ & $\begin{array}{l}19,686 \\
10.26 \%\end{array}$ & $\begin{array}{c}6065 \\
3.16 \%\end{array}$ & $\begin{array}{c}2703 \\
1.41 \%\end{array}$ & $\begin{array}{l}293 \\
0.15 \%\end{array}$ & $\begin{array}{c}191,890 \\
-\end{array}$ \\
\hline
\end{tabular}

\subsection{Existing Conductors for Transmission OHLs}

The recent evolution trend in the power systems, as mentioned in Section 1, imposes new challenges to the transmission and distribution system operators (with acronyms TSOs and DSOs, respectively), to face the higher uncertainty in the power flows and reducing the bottlenecks. Although increasing the flexibility of the power system remains a priority, reinforcing the power lines will be a necessity in the near future. The challenge is then to find conductors able to uprate the current lines (i.e., increase the thermal limit) while ensuring the same (or improved) mechanical performances. Innovation in this field has mainly concerned conductors indicated as High Temperature Low Sag (HTLS), capable of operating continuously at high temperatures (above $100^{\circ} \mathrm{C}$ ), but containing the 
sag due to elongation resulting from the high temperature [27]. The main commercially available solutions for HTLS conductors, shown in Figure 1 and whose characteristics can be found in Table 5, are as follows.

- Aluminium Conductor Steel Reinforced, ACSR, or Aluminium Conductor Steel Supported, ACSS, composed by annealed aluminium strands (or even trapezoidal wires, in the ACSS case) over a stranded steel core: this is the most commonly adopted solution for transmission OHLs;

- Aluminium Conductor Composite Reinforced, ACCR, typically composed by a high-temperature aluminium alloy over a composite core of aluminium fibers embedded in a pure aluminium matrix. The same structure is also used in (Z)TACIR conductors, in which the core is in INVAR (steel and nickel alloy with very low linear expansion coefficient);

- Gap-type Aluminium Conductor Steel Reinforced, G(Z)TACSR, consisting of an external thermal-resistant aluminium alloy (with a layer of trapezoidal wires), separated from the steel core by a gap filled with grease to allow the two layers to move independently. This ensures to apply the mechanical tension on the steel core only while increasing the aluminium cross-section for a reduced electrical resistance;

- Aluminium Conductor Composite Core, ACCC/TW, typically made of trapezoidal wires of thermal-resistant aluminium alloy over a core consisting of carbon fibers (in the inner part) surrounded by a coating of glass fibers. This configuration gathers the advantage of increased aluminium cross-section and weight lowering due to the use of a carbon fiber core.

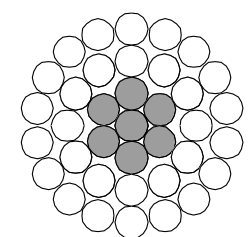

(a)

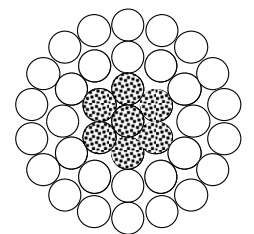

(b)

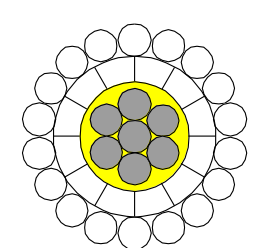

(c)

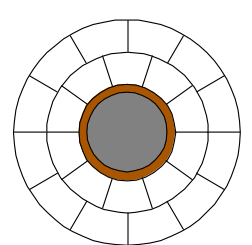

(d)

Figure 1. Main types of high temperature low sag (HTLS) conductors: (a) ACSR, ACSS; (b) ACCR, (Z)TACIR; (c) G(Z)TACSR; (d) ACCC/TW.

Table 5. Comparison of the main HTLS conductor types with ACSR.

\begin{tabular}{ccccc}
\hline & ACSR & ACCR & G(Z)TACSR & ACCC/TW \\
\hline Diameter $(\mathrm{mm})$ & 22.8 & 23.9 & 22.6 & 21.79 \\
\hline & $7 \times 2.8$ (Steel core) & $7 \times 2.9$ (Al core) & $7 \times 2.8$ (Steel core) & $7.11(\mathrm{Core})$ \\
Composition $(\mathrm{mm})$ & $26 \times 3.6$ (Al strands) & $26 \times 3.8$ (Al strands) & $10 \times 3.94(\mathrm{Al}$ TW) & $16 \times 4.95(\mathrm{Al}$ TW) \\
& & & $19 \times 3.1$ (Al strands) & \\
\hline Cross-section $\left(\mathrm{mm}^{2}\right)$ & 307.8 & 338 & 308.4 & 355.2 \\
Weight $(\mathrm{kg} / \mathrm{km})_{\mathrm{R}_{d c 20}{ }^{\circ} \mathrm{C}(\Omega / \mathrm{km})}$ & 1068 & 966 & 1098 & 948 \\
$\mathrm{R}_{a c 20}{ }^{\circ} \mathrm{C}(\Omega / \mathrm{km})$ & 0.1063 & 0.0945 & 0.111 & 0.0887 \\
Ampacity $(\mathrm{A})$ & 0.1065 & 0.0971 & 0.114 & 0.091 \\
Temperature $\left({ }^{\circ} \mathrm{C}\right)$ & 745 & 1332 & 1128 & 1227 \\
\hline
\end{tabular}

As reported in Table 5, the four conductor types, although having similar dimensions (diameter and cross-section), present significantly different ampacities and resistance values. In particular, comparing the traditional ACSR, for which the ampacity value is reported with reference to the temperature of $75^{\circ} \mathrm{C}$ assumed by the standards, with the ACCC/TW conductor, it can be noticed how, although having a lower diameter, the actual cross-section results higher, due to the trapezoidal wires and the smaller section required by the composite material core. As a result, the conductor resistance is decreased and the ampacity is higher than the ACSR. 


\section{Innovative Conductor for Transmission OHLs}

In this section, the innovative conductor proposed for transmission OHLs is presented. The following subsections discuss about the characteristics of the proposed conductor, with a focus on the experimental research concerning the materials to realize the core shell.

\subsection{Conductor Characteristics}

The conductor is designed to replace the traditional bimetallic conductor (ACSR) having overall cross-section of $308 \mathrm{~mm}^{2}$ and diameter of $\varphi=22.8 \mathrm{~mm}$, mainly employed in the 132-150 kV Italian subtransmission network. A section of the innovative conductor, denominated ACCM/TW (Aluminium Conductor Composite Multistrand-Trapeziodal Wires), is depicted in Figure 2, in which the external conductive part, the inner core and its shell are colored differently. The properties of the innovative conductor, compared to those of the traditional one, are reported in Table 6. Instead of being made of steel, the conductor core, in orange in Figure 2, is made of a composite material, mainly consisting of carbon fibers. This choice allows the same breaking load to have a conductor core with reduced section, with a significant decrease in weight and in thermal expansion respect to the traditional conductor $(1 / 10$ respect to steel). Furthermore, respect to already existing commercial options, having a single-stranded carbon fiber core, the proposed conductor presents a core divided in seven strands as it can be seen in Figure 2. Due to the thermal processes required in its manufacturing, carbon fiber composite materials tend to have a higher homogeneity in the external section, whereas the fibers assume inhomogeneous disposition in the inner parts [28].

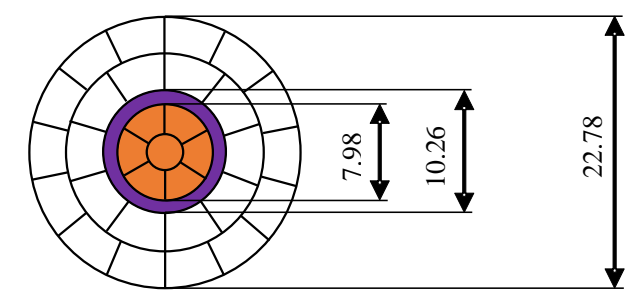

Figure 2. Section of the innovative ACCM/TW conductor with diameter $22.78 \mathrm{~mm}$.

Table 6. Main properties of the innovative conductor for transmission OHLs compared with its reference traditional conductor.

\begin{tabular}{ccc}
\hline & ACSR & ACCM/TW \\
\hline Diameter $(\mathrm{mm})$ & 22.8 & 22.78 \\
\hline & $7 \times 2.8$ (Steel core) & $1 \times 3 / 6 \times 2.49$ (Core) \\
Composition $(\mathrm{mm})$ & $26 \times 3.6$ (Al strands) & $1 \times 1$ (Al shell) \\
& - & $24 \times 3.13$ (Al layers) \\
\hline Cross-section $(\mathrm{mm})$ & 307.8 & 345.5 \\
Weight $(\mathrm{kg} / \mathrm{km})$ & 1068 & 989 \\
Breaking load $(\mathrm{kN})$ & 97.52 & 117.39 \\
$\mathrm{R}_{a c 20}{ }^{\circ} \mathrm{C}(\Omega / \mathrm{km})$ & 0.1065 & 0.0894 \\
Ampacity $(\mathrm{A})$ & 745 & 994 \\
Temperature $\left({ }^{\circ} \mathrm{C}\right)$ & 75 & 120 \\
\hline
\end{tabular}

For this reason, in this project, a stranded core is proposed, in order to contain the cross-section of each of the composite core strands, ensuring a better distribution of the mechanical stress on the core in correspondence of the clamps.

Moreover, the presence of multiple wires leads to several advantages that makes this solution much more interesting than the single wire core (i.e., ACCC-TW of Table 5), mainly from the safety point of view. Looking at the experience of other manufacturers, the single wire core (i.e., ACCC-TW of Table 5) has shown several safety problems due to the nature of carbon composite-a brittle and 
stiff material. Several single wire core (i.e., ACCC-TW of Table 5) breakages have been reported during the installation and also during the lifetime of the line usually within a short period after conductor installation but in some cases some years after installation. These accidents affect the carbon core, which is very sensitive to the bending external stress that can occur in the installation work. The problem is that this kind of breaks (since they affect just the carbon core and not the aluminium outer layer) are not visible from outside and cannot be detected by visually checking the conductor. For this reason the installation must be carried out with great care, avoiding excessive bending that could lead to core damage and the entire process must be constantly supervised, becoming quite complicated compared to other conductor installations. With a multiwire core the nature of the carbon composite material is not changed, but the seven-wire (multistrand) structure is much more flexible than the single carbon wire. This means that the core is much less sensitive to breakages. Another important feature of this kind of solution is that the consequences of a possible break are much less serious. In fact, if a wire breaks the other six ones guarantee the stability of the structure, leading to a much more safe transmission line. On opposite, every little damage of a single core (i.e., ACCC-TW) leads to the complete failure. Moreover, the ACCR solution has as main disadvantages the high cost and the brittleness due to the nature of the core material. Furthermore, the losses are not optimized as it can be seen from the higher electrical resistance compared to the ACCM.

The reduction of the core section and weight allows, for the same external diameter, an increase of the conductive part in aluminium. In addition, the trapezoidal strands allow a better filling factor than the traditional circular strands. In Table 6, the main characteristics of the innovative ACCM/TW conductor are reported, compared with the traditional ACSR ones. The shell, in purple in Figure 2, is realized in aluminium, as this material is the most suited to keep the core insulated from external humidity and guarantee durability for the expected OHL lifetime. A deeper discussion on this aspect is made in the following section.

\subsection{Experimental Research on Core-Coating Materials}

The carbon fiber composites, although offering excellent mechanical performance, are negatively affected by humidity due to the oxidation process that drastically degrades the characteristics of this material. Aiming at containing the conductor weight increase due to the coating, an important experimental part of the CalaJoule research project focused on the evaluation of the performance of polymeric materials $[29,30]$. The scope is to assess their suitability for realizing a shell for the core of the conductor capable of protecting it from oxidation (the area of application of the polymeric coating is highlighted in purple in Figure 2). Given the critical temperature conditions required $\left(180-200^{\circ} \mathrm{C}\right)$, the choice falls on thermally resistant polymers such as PEEK, PEKK, PEI, PPA and PPS. PEEK, PPS, PPA, and PEI.

The main characteristics required of the materials are the impermeability to oxygen and the preservation of the properties for long periods (at least four decades, supposed as the lifetime of an $\mathrm{OHL}$ ). The polymeric materials to be used as coating are mainly required to be resistant to continuous exposure to high temperatures $\left(140^{\circ} \mathrm{C}\right)$ and to avoid the flow of oxygen in order to prevent oxidation of the carbon fiber core.

After an initial screening among the best technopolymers available on the market, those having the best performance in relation to thermal properties were identified. The classes of technopolymers analyzed are as follows [16].

- PEEK, polyetheretherketone, is a semicrystalline thermoplastic technopolymer that can be used at high temperatures. It has high mechanical and chemical resistance, is resistant to abrasion, is not flammable, resists to high energy radiation.

- PEKK, polyetherketoneketone, is a semicrystalline thermoplastic polymer with high heat resistance, significant mechanical strength and rigidity, combined with good chemical resistance. It is an intrinsically fireproof material with limited smoke generation and low toxicity in case of fire. 
- PEI, polyetherimide, is an amorphous technopolymer that can be used continuously at high temperatures. Its properties also include high mechanical strength and rigidity even at high temperatures, dimensional stability for low moisture absorption, and good electrical properties. It is inherently flame retardant and chemically resistant and its electrical properties are stable even under varying temperature, humidity and frequency conditions.

- PPA, polyphthalamide, is a semicrystalline aromatic polyamide. Compared to polyamide 6.6 it is more mechanically resistant, more rigid, less sensitive to moisture, and has improved thermal properties, fatigue, and creep resistance factors that make it applicable in a wide range of sectors;

- PPS, polyphenylene sulfide, is a semicrystalline polymer with excellent thermal resistance. This material is characterized by inherent low flammability and good chemical resistance. It has very low moisture absorption, high mechanical strength, and dimensional stability.

For a selection of these materials (shown in Figure 3), performance was assessed through the following analysis; chemical (FT-IR), physical-mechanical (hardness, density, and bending properties), thermal (TGA and DSC), and dynamic-mechanical (DMA). Creep resistance was also evaluated and oxygen permeability measured. The samples have undergone an accelerated aging test to assess their degradation according to the expected lifetime of an OHL (40 years). The approximated model in [25] has been employed to evaluate the deterioration of the material properties, applying temperatures in the range of 200 to $250^{\circ} \mathrm{C}$.

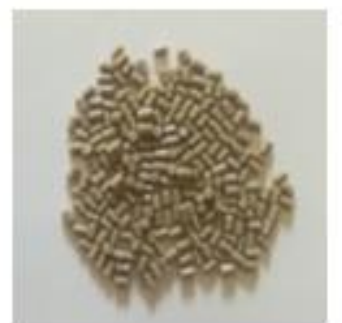

PEEK

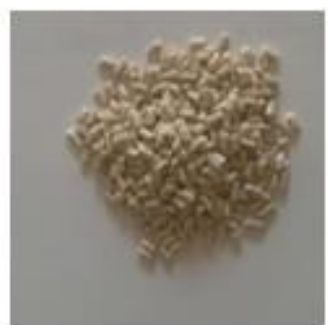

PPS

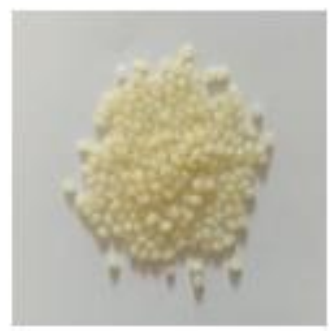

PPA

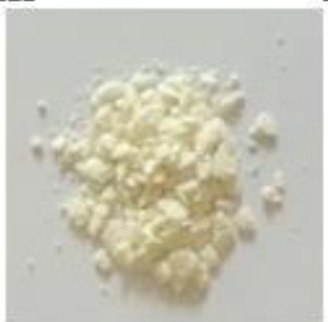

PEKK

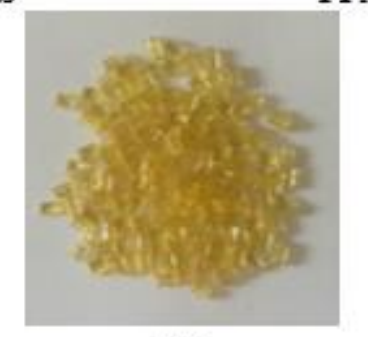

PEI

Figure 3. Polymers tested in the project.

In Table 7, a list of the tested polymers is reported along with the measured oxygen permeability (considered a discriminatory property) measured according to ISO $15105-2$, at $25^{\circ} \mathrm{C}, 50 \%$ R.H.

Table 7. List of the tested polymers; the highlighted ones are those with the best performance overall.

\begin{tabular}{|c|c|}
\hline $\begin{array}{l}\text { Material } \\
\text { Type }\end{array}$ & $\begin{array}{c}\text { Permeability } \\
\left(\mathrm{cm} \mathrm{cm}^{3} /\left(\mathrm{m}^{2} 24 \mathrm{~h} \text { bar }\right)\right)\end{array}$ \\
\hline PEEK & 235 \\
\hline PEKK & 796 \\
\hline PPS & 4.2 \\
\hline PEI & 2.3 \\
\hline PPA & 9.7 \\
\hline
\end{tabular}


The polymers that have shown the best performance are the polyetherimide and the polyphenylene sulfide.

However, after accelerated aging at $250^{\circ} \mathrm{C}$, the mechanical and oxygen permeability properties have shown a degradation, which leads to the conclusion that these materials cannot guarantee protection to the conductor's core under such severe conditions $\left(\mathrm{T}=140{ }^{\circ} \mathrm{C}\right)$ and for long periods (40 years).

The treatment of samples subjected to accelerated aging at $200{ }^{\circ} \mathrm{C}$, following the procedure described above, takes 7.6 months to estimate 40 years of operation at $140{ }^{\circ} \mathrm{C}$. In practice, the duration of the test was 2.5 months because already after this period all the materials considered showed clear signs of degradation, such as to prevent the measurement of oxygen permeability.

In Figure 4, the thin film samples used for the aging test are shown in the initial state and after the process. The films subjected to this aging test had the necessary geometry for the permeability tests, therefore thin films. Since the degradation of the material starts from the external surface, in contact with the air, for thin films it can affect the entire section of the film in a relatively short time. This leads to embrittlement and cracking that affects the oxygen permeability measurement.

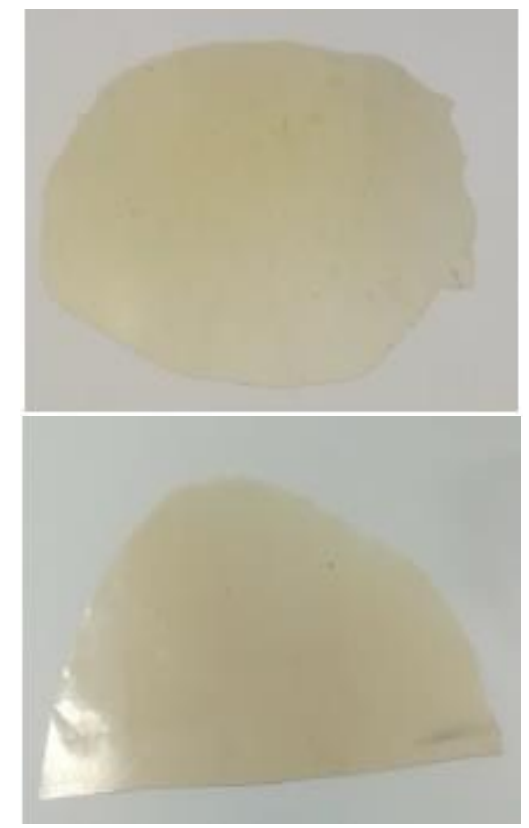

(a)

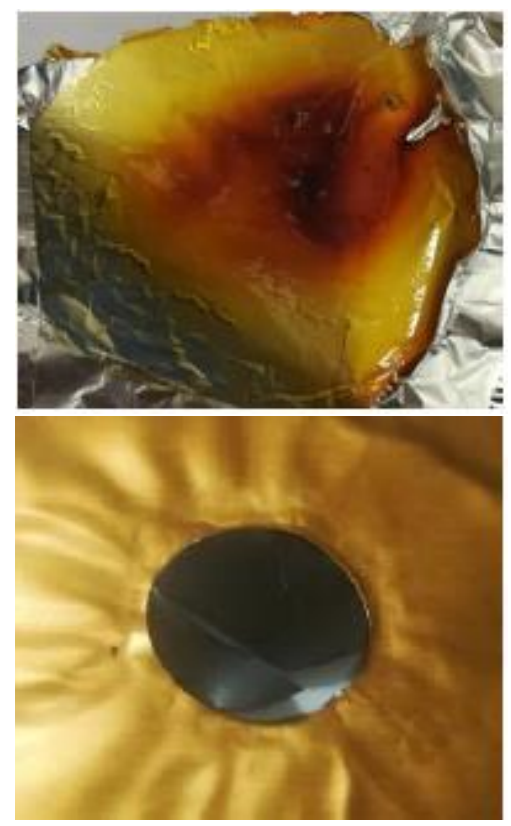

(b)

Figure 4. Thin film samples of PEI (Top) and PPS (Bottom) before (a) and after (b) the aging process at $200{ }^{\circ} \mathrm{C}$.

For this reason, it has been decided to apply the aging process to thicker samples (4 mm), but with a temperature of $250{ }^{\circ} \mathrm{C}$, in order to reduce the measurement time while assuming the same expected lifetime of 40 years. In Figure 5, the $4 \mathrm{~mm}$ samples are shown for three stages of the aging test: start time (1), after $2.5 \mathrm{~h}$ (2), and at the end of the test, after 7.2 days (3). As it can be seen, after $2.5 \mathrm{~h}$ the samples show a color variation and, in the case of PEI, the formation of surface swellings. At the end of the aging process, all the samples show significant color variation. In particular, the samples of PEI are partly deformed and have cavities inside. 


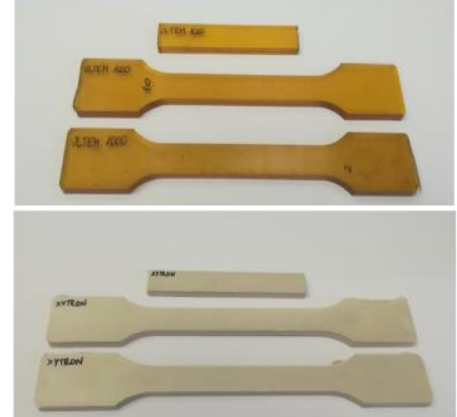

(a)

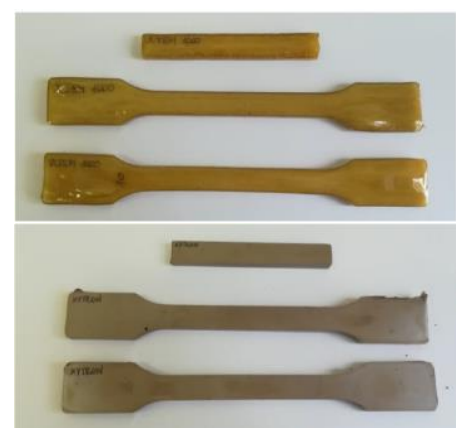

(b)

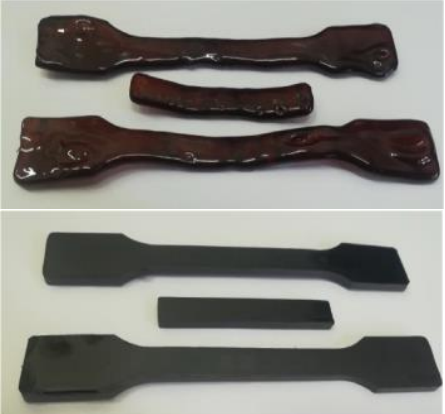

(c)

Figure 5. Four millimeter samples of PEI (Top) and PPS (Bottom) before (a) and after the aging process at $250{ }^{\circ} \mathrm{C} ;(\mathbf{b})$ after $2.5 \mathrm{~h}$ and (c) after 7.2 days.

The mechanical properties of the samples after the test have been compared with those at the start of it as reported in Table 8, where the flexural strength is reduced by $20 \%$ for PEI and by $57 \%$ for PPS (measured according to ISO 178).

Table 8. Flexural mechanical properties of the selected materials before and after the aging test.

\begin{tabular}{ccccc}
\hline \multirow{2}{*}{ Material } & \multicolumn{2}{c}{ Flexural Modulus (MPa) } & \multicolumn{2}{c}{ Flexural Strength (MPa) } \\
\cline { 2 - 5 } & Before & After & Before & After \\
\hline PEI & 3258 & 2700 & 110 & 89 \\
PPS & 2055 & 2330 & 70 & 30 \\
\hline
\end{tabular}

In order to run an oxygen permeability test on the samples after the aging test, the thin film samples shown in Figure 6 have been obtained from the $4 \mathrm{~mm}$ samples in Figure 5. The visible degradation of these samples did not allow running a permeability test, since the oxygen permeability of the material was outside of the detectable range of the instrument.

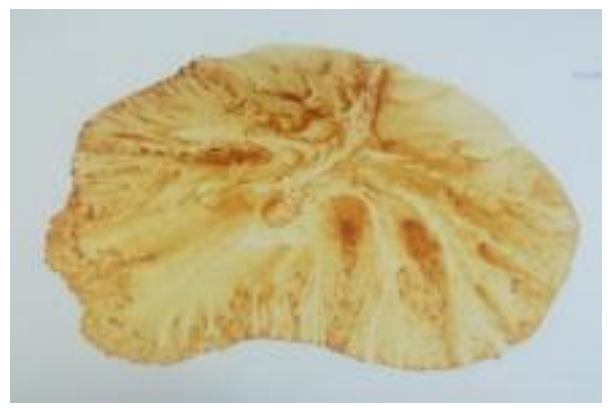

(a)

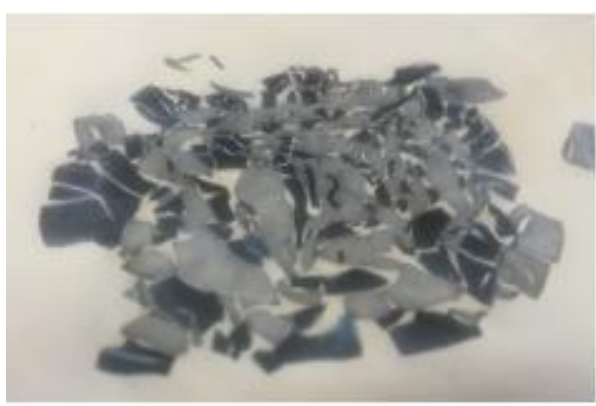

(b)

Figure 6. Thin film samples obtained from the $4 \mathrm{~mm}$ samples of PEI (a) and PPS (b) after the aging test.

The degradation of the mechanical properties and especially of the oxygen permeability, led to the conclusion that none of the tested materials (which are the techno-polymers with the best performances currently on the market) are suited to be used as core-insulation material for the innovative conductor. As a result, although leading to a higher overall weight increase, it has been decided to adopt an aluminium shell, since this material has well-known oxygen-shielding and temperature resistance properties, without suffering from the degradation detected for polymeric materials. 


\subsection{Clamping Equipment for the Proposed ACCM/TW Conductor}

Part of the research concerned the study of innovative solutions for the clamping equipment and accessories necessary for the installation of the innovative conductors in transmission OHLs, given its constructive peculiarities. The research has focused only on the direct contact clamping because its improvement could reduce losses and exploit the innovative conductor's full potential. By its very definition, the clamp is an element of mechanical, electrical and chemical discontinuity in the line conductor and therefore can often be a weak point. The main requirements for a good terminal block are therefore

- having an electrical conductivity at least equal to that of the conductor with a negligible contact resistance (to reduce heating of the terminal) and

- avoiding corrosion due to electrolytic torques deriving from contact between metals of different types.

All the parts with direct contact with the conductor have been designed using a high conductivity aluminium alloy (EN AW-1050A). In order to contain the corrosion effects, bolts, and nuts have been designed in austenitic stainless steel, whereas the suspension parts (i.e., not in direct contact with the conductive parts of the conductor) are realized in aluminium alloy EN AW-44100, having a reduced copper content.

\section{Innovative Conductor for Distribution OHLs}

For the distribution network, the selected solution is an All Aluminium Alloy Conductor (AAAC) with low resistivity or high conductivity (IACS), and hence the innovative conductor has been named as Super High Conductivity (AAAC-SHC). An AAAC-SHC conductor with a diameter of $17.25 \mathrm{~mm}$ (see Figure 7) has been developed and its characteristics are compared with the most similar traditional standard AAAC conductors used in the Italian distribution/subtransmission networks (Aldrey 185/37 and AAAC Al 3). The Aldrey 185/37 conductor, together with other commonly used conductors in the Italian distribution network is considered for the benefit analysis in Section 5. As it can be seen from Table 9, although having a reduced cross-section with reference to Aldrey 185/37, the innovative conductor presents a lower resistance and a higher ampacity due to an increased IACS (57.3\% versus $53 \%$ in the traditional one). The development of the AAAC-SHC $17.25 \mathrm{~mm}$ conductor is the result of an accurate study of aluminium alloys properties, in terms of electrical conductivity and mechanical properties, together with a careful analysis of chemical composition and microstructure of the alloys. This research has permitted to develop a material with a higher electrical conductivity compared to the traditional aluminium alloy used for conductors (AAAC), maintaining the same tensile strength. As it can be seen in Figure 8, the conductivity increase is of several \%IACS compared to the traditional aluminium alloy AL2 $(\%$ IACS = 52.5), AL3 $(\% \mathrm{IACS}=53)$, and AL4 $(\% \mathrm{IACS}=52.9)$.

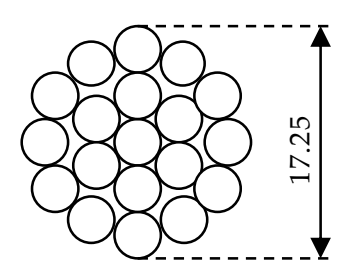

Figure 7. Section of the AAAC-Super High Conductivity (SHC) conductor with diameter $17.25 \mathrm{~mm}$. 
Table 9. Main properties of the innovative conductor for distribution OHLs compared with two reference traditional conductors.

\begin{tabular}{cccc}
\hline & Aldrey 185/37 & AAAC A1 3 & AAAC-AL-SHC \\
\hline Diameter $(\mathrm{mm})$ & 17.64 & 15.25 & 17.25 \\
Composition $(\mathrm{mm})$ & $37 \times 2.52$ & $19 \times 3.45$ & $19 \times 3.45$ \\
Cross-section $\left(\mathrm{mm}^{2}\right)$ & 184.5 & 177.6 & 177.6 \\
Weight $(\mathrm{kg} / \mathrm{km})$ & 508.8 & 488 & 488 \\
Breaking load $(\mathrm{kN})$ & 52.59 & 52.4 & 52.4 \\
$\mathrm{R}_{a c 20}{ }^{\circ} \mathrm{C}(\Omega / \mathrm{km})$ & 0.1799 & 0.1862 & 0.1724 \\
IACS & $53 \%$ & $53 \%$ & $57.3 \%$ \\
Ampacity $(\mathrm{A})$ & 398 & 433 & 450 \\
Temperature $\left({ }^{\circ} \mathrm{C}\right)$ & 75 & 75 & 75 \\
\hline
\end{tabular}

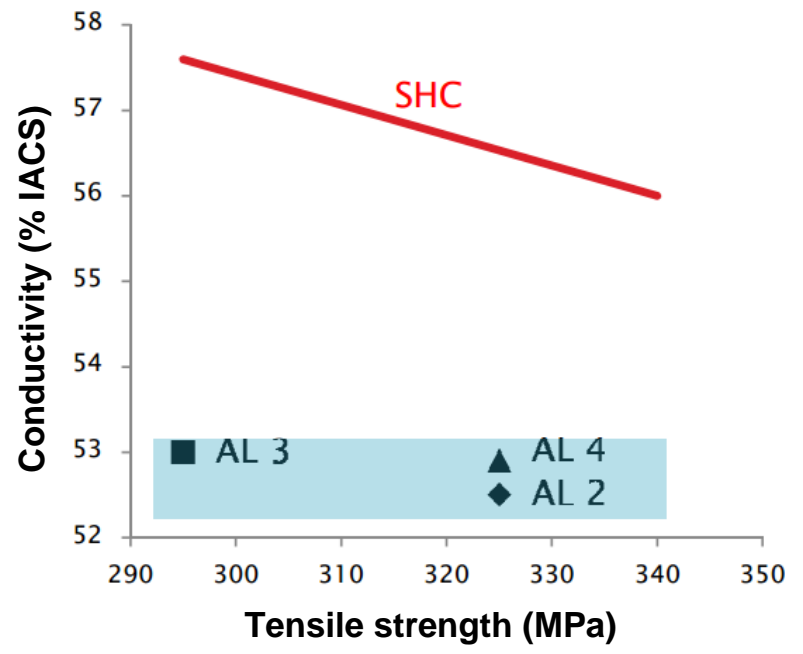

Figure 8. Comparison between traditional alloys (AL 2, AL 3, and AL 4 in azure area) and AAAC-SHC.

\section{Assessment of Benefits from the Installation of Innovative Conductors}

In this section, the procedure for assessing the impact of the installation of the innovative conductors on the Italian network is outlined, and then the methodology is applied to compare the performance of the innovative conductors introduced in the previous sections with the traditional ones. The aim is to analyze the benefits resulting from the replacement of the conductors in the line sections that would not require changes in the support structures, by considering the types introduced in Section 2.

\subsection{Benefit Assessment Methodology}

A fully detailed representation of the national power system could be very difficult and, still, does not remove all sources of errors in building the model, given the necessity of a high detail in the information needed, not only on the network structure, but, most importantly, on the load trend over a long period. Furthermore, this effort is not necessary for the scope of this work, which is comparing the effects on the efficiency of the power lines as a whole. In this work, instead, a simplified approach to the evaluation of the operative conditions of an OHL is presented in [14] and reported in the following.

The methodology, based on the Ossanna's theorem [14], under the hypothesis of a symmetric network and balanced loading on the phases, makes use of the single-phase OHL equivalent to analytically evaluate the operative state of a line given the complex power at its receiving end, once the voltage at the sending end is assumed.

By considering the single-phase equivalent in Figure 9a, converted to its per unit representation in Figure $9 b$, the current in the vector diagram in Figure $9 c$ is obtained as in (1), as a function of the receiving end voltage $\underline{u}$ and complex power $\underline{s}$ (values in p.u., superscript ${ }^{*}$ stands for complex 
conjugate). From (2), the relation between complex power and sending end voltage can be written as in (3), in which the angle $\gamma$ results from the difference between the impedance argument $\psi$ and the load angle $\varphi$.

$$
\begin{gathered}
\underline{i}=\frac{\underline{s}^{*}}{\underline{u}^{*}}=\frac{1-\underline{u}}{e^{j \psi}} \\
\underline{u}^{*}-u^{2}=\underline{s}^{*} \cdot e^{j \psi} \rightarrow u \cdot e^{j \delta}-u^{2}-s \cdot e^{j \gamma}=0
\end{gathered}
$$

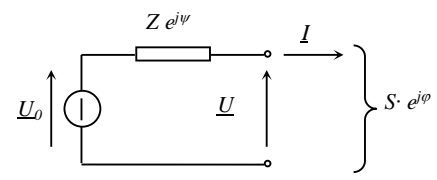

a)
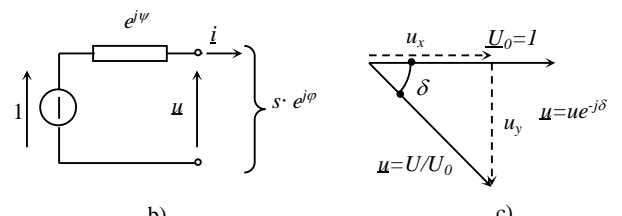

Figure 9. (a) Single-phase equivalent of an OHL from the receiving end, (b) its equivalent per unit representation, and (c) vector diagram of the voltage.

Splitting real and imaginary parts of (2) as in (3) it can be seen how, once the receiving end complex power is defined, the imaginary part of $\underline{u}$ is constant. By solving the first equation in (3), the real part is calculated as in (4), which define the two sending end voltage vectors $\underline{u}^{\prime}$ and $\underline{u}^{\prime \prime}$ in (5), of which $\underline{u}^{\prime}$ is the most important, given the low magnitude of $\underline{u}^{\prime \prime}$, with the constraint $\xi \geq 0$, which represents the physical feasibility.

$$
\begin{gathered}
\left\{\begin{array}{l}
u_{x}^{2}+u_{y}^{2}-u_{x}+s \cos \gamma=0 \\
-u_{y}+s \sin \gamma=0
\end{array}\right. \\
u_{x}=\frac{1}{2} \pm \sqrt{\frac{1}{4}-s \cos \gamma-(s \sin \gamma)^{2}}=\frac{1}{2} \pm \xi \\
\left\{\begin{array}{l}
\underline{u}^{\prime}=\frac{1}{2}+\xi-j \sin \gamma \\
\underline{u}^{\prime \prime}=\frac{1}{2}-\xi-j s \sin \gamma
\end{array}\right.
\end{gathered}
$$

By considering the line representation in Figure 9a, the well-known relation (5) links the sending bus voltage and current (with subscript 1 ) to those at the receiving bus (with subscript 2). Under the assumption of symmetry and reciprocity of the line model (so that $\underline{A}=\underline{D}$ and $\underline{A} \underline{D}-\underline{B} \underline{C}=1$ ), (6) is derived. At this point, noting that $\underline{U}_{1}=\underline{A}_{\underline{U}} \underline{U}_{20}$, where $\underline{U}_{20}$ is the no-load voltage at the receiving end, and remembering that $\underline{Z}=\underline{B} / \underline{A}$ the current $\underline{I}_{1}$ can be written as in (7).

$$
\begin{array}{r}
\left\{\begin{array}{l}
\underline{U}_{1}=\underline{A U}_{2}+\underline{B I}_{2} \\
\underline{I}_{1}=\underline{C U}_{2}+\underline{D I}_{2}
\end{array}\right. \\
\left\{\begin{array}{l}
\underline{U}_{2}=\underline{A U}_{1}-\underline{B I}_{1} \\
\underline{I}_{2}=-\underline{C U}_{1}+\underline{D I}_{1}
\end{array}\right. \\
\underline{I}_{1}=\frac{\underline{A U}_{1}-\underline{U}_{2}}{\underline{B}}=\frac{\underline{U}_{1}-\underline{U}_{2} / \underline{A}}{\underline{B} / \underline{A}}=\frac{\underline{A U}_{20}-\underline{U}_{2} / \underline{A}}{\underline{Z}}
\end{array}
$$


If, at this point, the base values are defined as $U_{b}=\left|U_{20}\right|, S_{b}=U_{b}{ }^{2} /|\underline{Z}|$, and $Z_{b}=|\underline{Z}|$, the per unit version of (8) is given by (9). Therefore, the complex power $s_{1}$ at the sending end of the line is obtained as in (10), in which $\alpha$ is the argument of $\underline{A}$.

$$
\begin{gathered}
\underline{i}_{1}=\frac{\underline{s}_{1}^{*}}{\underline{A}^{*}}=\frac{\underline{A}^{-}-\underline{u}_{2} / \underline{A}}{e^{j \psi}} \\
\underline{s}_{1}=\left(A^{2}-\underline{u}^{*}{ }^{*} e^{j 2 a}\right) e^{j \psi}
\end{gathered}
$$

By this approach, once the complex power is known at the receiving end and the sending end voltage is set, the receiving end voltage $\underline{u}_{2}$ is obtained using the first equation in (5). At this point, the power flow on a line can be analytically calculated, since the sending end complex power is given by (10). This procedure is applied in the following sections to evaluate the Joule losses of the transmission and distribution OHLs.

\subsection{Transmission Grid OHLs}

For this network level, the presently installed standard conductors that may be replaced by the proposed innovative conductor are those reported in Table 10. This is a selection of the OHLs in the transmission grid having higher resistance per unit length and up to the same breaking load as the innovative conductor introduced in Section 3.1.

\begin{tabular}{|c|c|c|c|c|c|c|}
\hline Code & $\begin{array}{l}\text { Cross-Section } \\
\quad\left(\mathrm{mm}^{2}\right)\end{array}$ & $\begin{array}{c}\text { External } \\
\text { Diameter } \\
(\mathrm{mm})\end{array}$ & $\begin{array}{c}\text { Breaking } \\
\text { Load } \\
(\mathrm{daN})\end{array}$ & $\begin{array}{c}\text { Electrical Resistance } \\
\text { at } 20^{\circ} \mathrm{C} \\
(\Omega / \mathrm{km})\end{array}$ & $\begin{array}{c}\text { Thermal Rating } \\
\text { Current } \\
I_{R}(\mathrm{~A}) \\
\end{array}$ & $\begin{array}{c}\text { Thermal Rating } \\
\text { Power } \\
P_{R}(\mathrm{MW}) \\
\end{array}$ \\
\hline $42 / 6+1$ & 42.41 & 9 & 1613 & 0.6766 & 175.9 & 113.4 \\
\hline $68 / 12+7$ & 67.69 & 13.4 & 6195 & 0.4266 & 322.9 & 208.3 \\
\hline $128 / 26+7$ & 127.6 & 15.85 & 4909 & 0.2261 & 407.1 & 262.6 \\
\hline $191 / 26+7$ & 191.2 & 19.38 & 7122 & 0.1509 & 531.4 & 342.8 \\
\hline $212 / 30+7$ & 212.0 & 21 & 9866 & 0.1362 & 589.6 & 380.3 \\
\hline $265 / 26+7$ & 264.6 & 22.8 & 9752 & 0.1090 & 655.0 & 422.5 \\
\hline
\end{tabular}

Table 10. Potentially replaceable standard ACSR conductors.

The ampacity (hence the transmission capacity) of the potentially replaceable OHLs has been determined using the CEI 11-60 standard [31]. The current flow rates at the thermal limit, i.e., the current value for which the line can be operated for an unlimited period of time with a minimum probability of discharge and with acceptable aging of the line equipment, are defined in relation to the type of line, its position in the national territory, the seasonality and the operating conditions. Referring to Table 11, taken from [31], the current rating of the lines in Table 10 is calculated with reference to zone " $\mathrm{A}$ " (locations with an altitude below $800 \mathrm{~m}$ above sea level in central and southern Italy and the islands) and a seasonal period defined by the standard as "Period $\mathrm{F}^{\prime \prime}$ (cold period, between October and April). Since the reference conductor for the standard is the unified ACSR with diameter $\varphi=31.5 \mathrm{~mm}$, it is possible to determine the flow rates for different size conductors by means of (11):

$$
I_{R}=\left(0.14 \cdot \phi^{2}+30.8 \cdot \phi-110\right) \cdot I_{0} \cdot 10^{-3}
$$

where the diameter $\varphi$ is expressed in (mm) and the current $I_{0}$ (deduced from Table 11) is in (A). 
Table 11. Thermal limit current for the reference conductor as for standard CEI 11-60 (Adapted with permission from [31], CEI, 2005).

\begin{tabular}{|c|c|c|c|c|}
\hline \multirow{3}{*}{ Line Voltage Rating (kV) } & \multicolumn{4}{|c|}{ Thermal Limit Current of the Reference Conductor (A) } \\
\hline & \multicolumn{2}{|c|}{ Zone A } & \multicolumn{2}{|c|}{ Zone B } \\
\hline & Period C & Period F & Period C & Period F \\
\hline 380 & 740 & 985 & 680 & 770 \\
\hline 220 & 665 & 905 & 610 & 710 \\
\hline $132 \div 150$ & 620 & 870 & 575 & 675 \\
\hline
\end{tabular}

Table 1 shows that, among the ACSR conductors listed in Table 10, the one with higher extension on the HV and EHV networks is the 265/26 + 7. For this reason, in the following, the assessment of benefits from the substitution of traditional conductors takes into account the total extension of this type of conductor $(443.3 \mathrm{~km})$.

To find the value of the energies lost over the lifetime of the line, it is necessary to build the equivalent single-phase model of the line. First, the per unit length resistance of the conductor is calculated by the procedure explained in [12] and adapted to the operating temperature by means of the well-known equation

$$
r_{50^{\circ} \mathrm{C}}=r_{20^{\circ} \mathrm{C}} \cdot\left[1+\alpha_{20^{\circ} \mathrm{C}}\left(50^{\circ} \mathrm{C}-20^{\circ} \mathrm{C}\right)\right]
$$

where $\alpha_{20}{ }^{\circ} \mathrm{C}$ stands for the temperature coefficient of resistance at $20{ }^{\circ} \mathrm{C}$ for aluminium in $\left(1 /{ }^{\circ} \mathrm{C}\right)$, whereas an operating temperature of $50^{\circ} \mathrm{C}$ is assumed. This is a mere assumption, since the conductor's actual working temperature depends on the thermal regime that is established, as a result of the current flow, air temperature, and wind speed and direction with respect to the line axis.

In order to build the equivalent single-line model of the OHL, the tower type depicted in Figure 10 is considered. Along with the distances among the phases and respect to the ground, it can be noted that a maximum sag of $10 \mathrm{~m}$ is considered in the model. With these assumptions, the electrical parameters obtained for the OHL equipped with the traditional conductor and with the innovative one are reported in the figure as well. It should be noted that the resistance value has been increased by $3 \%$ in order to take into account the additional losses due to jumpers and clamping equipment.

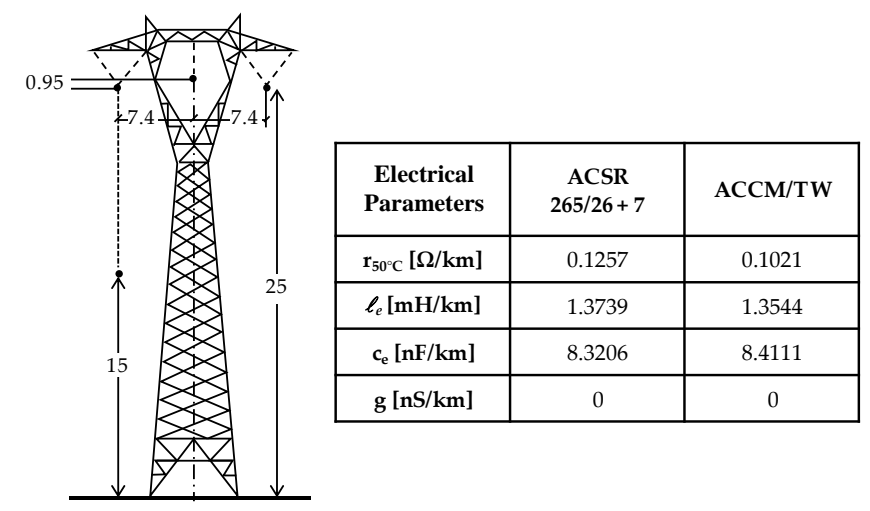

Figure 10. HV OHL case study: tower layout and per unit length electrical parameters.

Once the electrical parameters of the OHL are calculated, the methodology discussed in Section 5.1 is used to determine the Joule losses given the complex power withdrawn at the receiving end of the OHL. By assuming a duration curve of the type in Figure 11 (by hypothesis having the same trend as the national typical demand curve), the values are obtained by translating the curve according to the maximum value given by the above mentioned ampacity evaluation. In this case, as indicated in Table 10, for this conductor the maximum power is set at $422.5 \mathrm{MW}$, having assumed a thermal rating current $I_{R}$ of 655 A with a power factor of 0.98 (typical of the power flows on the transmission grid). 


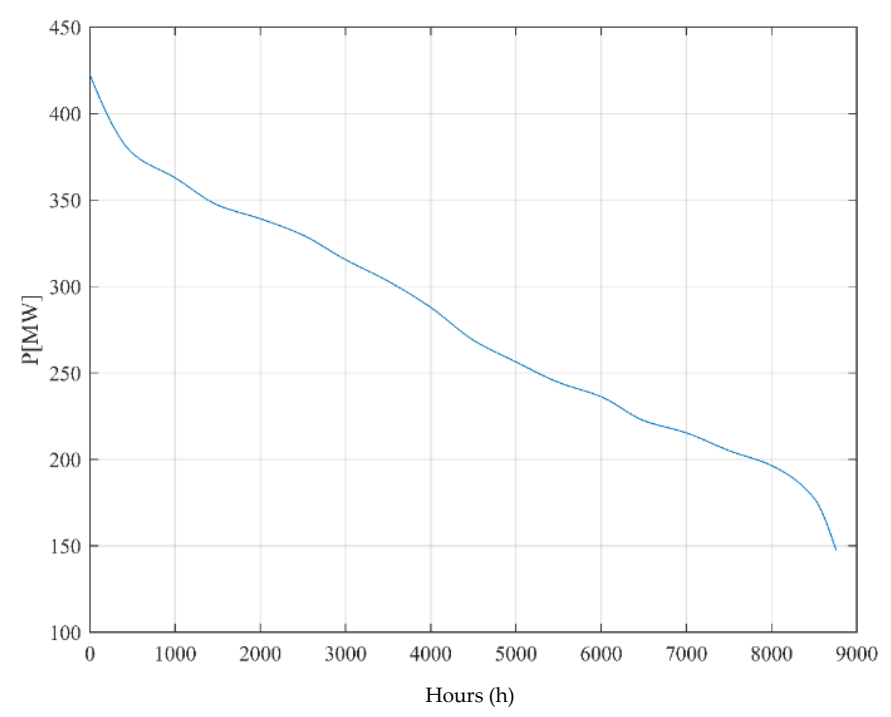

Figure 11. Duration curve assumed for the HV OHL case study.

As detailed in [13], the load-duration curve can be discretized in segments having a given duration $\Delta \tau$, so that the active power loss $\Delta p$ is deduced for every load power value and the annual joule losses (AJL) energy can be calculated by just multiplying $\Delta p$ by the respective time step. At this point, by assuming a constant electricity generation cost ( $40 € / \mathrm{MWh}$ is used in this study [32]), it is possible to have an indication of the Annual Cost of Losses (ACL), calculated as

$$
\mathrm{ACL}=\mathrm{AJL} \cdot C_{m L}(€)
$$

which can be actualized for each year in the OHL's lifetime by means of a discount rate $i$ (here assumed as $5 \%$ as in (14):

$$
\mathrm{AACL}=\frac{(1+i)^{n}-1}{i(1+i)^{n}} \cdot \mathrm{ACL}(€)
$$

In Table 12, the results for the transmission OHL equipped with the innovative ACCM/TW conductor are compared with those obtained with the traditional ACSR conductor. With the mentioned assumptions, if the entire extension of the ACSR $22.8 \mathrm{~mm}$ conductor on the HV and EHV Italian grids were replaced by the innovative conductor, the Joule power losses reduction would be of about $54.3 \mathrm{GWh}(-18.8 \%)$. This amounts to over 2 million of euro in savings every year for reduced electricity generation needs, which results in an actualized cost (over the 40-year expected OHL lifetime) of over 37 million of euro.

Table 12. Comparison between traditional and innovative conductors for HV OHLs.

\begin{tabular}{cccccc}
\hline Losses & & ACSR & ACMM/TW & $\Delta$ & $\boldsymbol{\Delta} \%$ \\
\hline Annual Joule Losses (AJL) & $(\mathrm{GWh})$ & 288.796 & 234.471 & 54.325 & \\
Annual Cost of Losses (ACL) & $(\mathrm{M} €)$ & 11.55 & 9.379 & 2.17 & $-18.81 \%$ \\
Actualized Annual Cost of Losses (AACL) & $(\mathrm{M} €)$ & 198.22 & 160.932 & 37.288 & \\
\hline
\end{tabular}

From an environmental point of view, the replacement of the traditional conductor with the innovative one would result in a saving of $21.187 \mathrm{kt}$ per year of carbon dioxide, which becomes $847.475 \mathrm{kt}$ in the expected 40-years lifetime. These values are obtained considering an emission of $0.39 \mathrm{t} / \mathrm{MWh}$ of $\mathrm{CO}_{2}$ [32]. 


\subsection{Distribution Network OHLs}

As for the previous case, a list of potentially replaceable conductors has been identified for the distribution network context. The traditional conductors reported in Table 13 are those having higher per unit length resistance and lower breaking load with respect to the innovative conductor ones, among those listed in the state of the art. The thermal rating current $I_{R}$ has been calculated in a deterministic way (since the standard CEI 11-60 is not applicable to MV and LV OHLs) by means of the approach developed by Shurig and Frick in 1930 and summarized in [33]. It was decided not to consider the presence of solar irradiation (assumed equal to $1000 \mathrm{~W} / \mathrm{m}^{2}$ ) in order to have a higher thermal rating in the comparison.

Table 13. Potentially replaceable distribution network conductors.

\begin{tabular}{|c|c|c|c|c|c|c|c|c|c|}
\hline Material & Code & $\begin{array}{l}\text { Cross-Section } \\
\quad\left(\mathrm{mm}^{2}\right)\end{array}$ & $\begin{array}{c}\text { External } \\
\text { Diameter } \\
(\mathrm{mm})\end{array}$ & $\begin{array}{c}\text { Breaking } \\
\text { Load } \\
(\mathrm{daN})\end{array}$ & $\begin{array}{l}\text { Resistance } \\
\text { at } 20^{\circ} \mathrm{C} \\
(\mathrm{Ohm} / \mathrm{km})\end{array}$ & $\begin{array}{l}\text { Thermal } \\
\text { Rating } \\
\text { Current } \\
\text { I }_{\mathbf{R}}(\mathrm{A})\end{array}$ & $\begin{array}{l}\text { Potential } \\
\text { Losses } \\
\text { Reduction } \\
(\%)\end{array}$ & $\begin{array}{l}\text { Potential } \\
\text { Losses } \\
\text { Cost } \\
\text { Savings } \\
\text { (M€) }\end{array}$ & $\begin{array}{l}\text { Potential } \\
\quad \mathrm{CO}_{2} \\
\text { Emissions } \\
\text { Reduction } \\
\quad(\mathbf{k t})\end{array}$ \\
\hline \multirow{2}{*}{ Copper } & $70 / 19$ & 68.34 & 10.7 & 27.33 & 0.2678 & 281 & 35.80 & 16.820 & 420.541 \\
\hline & $95 / 19$ & 94.76 & 12.6 & 37.9 & 0.1831 & 357 & 5.81 & 3.000 & 75.191 \\
\hline Aluminium & $120 / 19$ & 125.50 & 14.5 & 20.03 & 0.2292 & 332 & 24.91 & 1.157 & 11.282 \\
\hline \multirow{4}{*}{ Aldrey } & $70 / 19$ & 68.34 & 10.7 & 19.48 & 0.484 & 209 & 64.70 & 10.500 & 102.065 \\
\hline & $95 / 19$ & 94.76 & 12.6 & 27.01 & 0.3491 & 258 & 50.90 & 0.490 & 4.758 \\
\hline & $120 / 19$ & 125.50 & 14.5 & 35.77 & 0.2636 & 310 & 34.80 & 0.360 & 3.544 \\
\hline & $150 / 37$ & 147.10 & 15.75 & 41.93 & 0.2253 & 344 & 23.60 & 0.260 & 2.5285 \\
\hline
\end{tabular}

As already mentioned, the actual trend in electricity usage and production will require in the near future a reinforcement of the distribution network. Increasing the conductor's cross-section would then be a solution for reducing the risk of bottlenecks in the power flow distribution. For this reason, the traditional conductors included in this study have cross-sections even below the one of the innovative one (up to $70 \mathrm{~mm}^{2}$ ), as the innovative conductor may be used as a reinforcement of these current OHLs.

The tower type for the distribution grid's case study OHL is depicted in Figure 12, consisting of a three-phase line with $10.5 \mathrm{~m}$ tall towers. As already mentioned in Section 4 , the closest match with the standard conductors presently installed, listed in Table 13, is the Aldrey 185/37 having a diameter of $17.64 \mathrm{~mm}$ and a cross-section of $184.5 \mathrm{~mm}^{2}$. The parameters for the single-line equivalent circuit of the OHL are reported in Figure 12 for both the reference standard conductor and the innovative one. The duration curve of the line load is reported in Figure 13, scaled according to the line thermal rating power in Table 13.

The results of the benefit analysis methodology discussed in Section 5.1 are detailed in comparison with the reference Aldrey conductor in Table 14. Replacing the total extension of the traditional Aldrey conductor would result in a Joule power losses reduction on a yearly basis of $1.17 \mathrm{GWh}$, corresponding to a decrease by $4 \%$. The estimated cost saving is about $47 \mathrm{k} €$ per year, which corresponds to an actualized cost reduction of $804 \mathrm{k} €$ (with the same assumptions about OHL lifetime and discount rate as in the previous section). The potential $\mathrm{CO}_{2}$ emissions savings is estimated as $457 \mathrm{t}$ per year. 


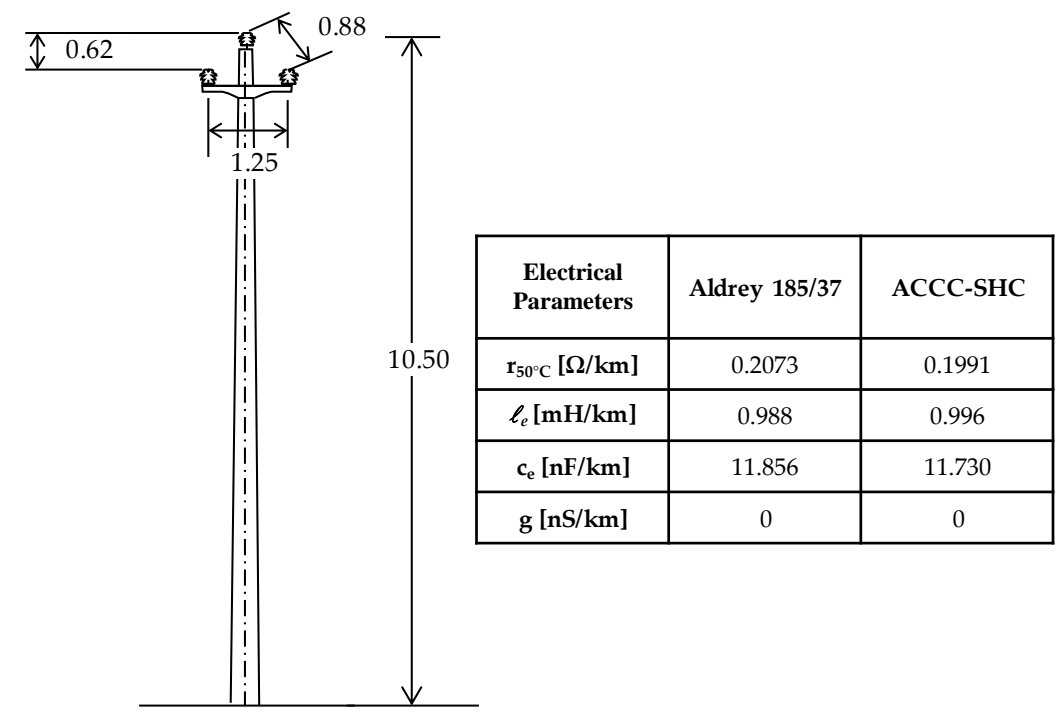

Figure 12. MV line case study tower layout.

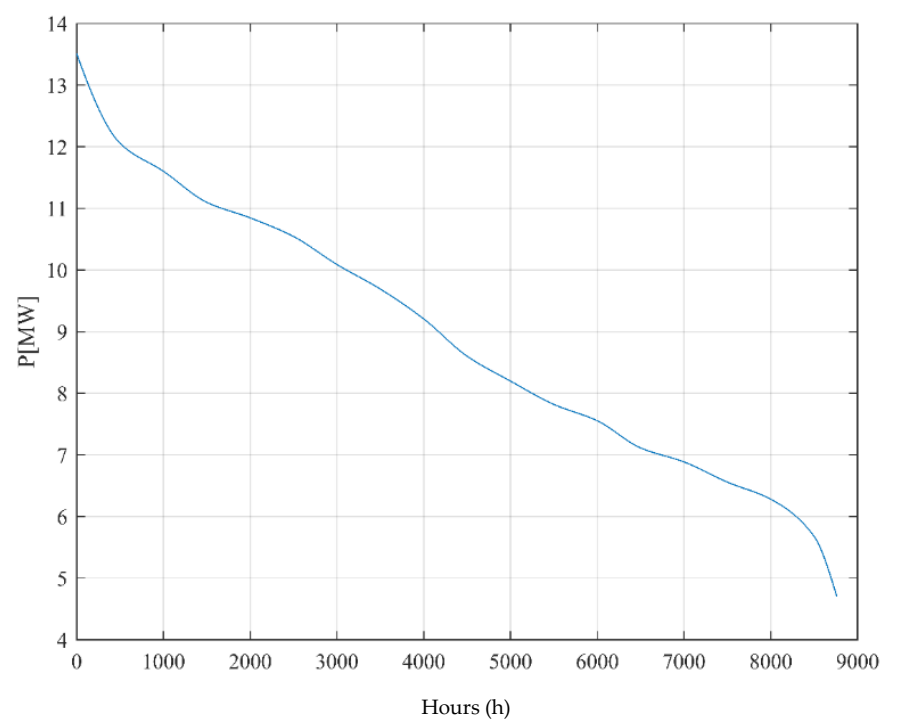

Figure 13. Duration curve assumed for the distribution OHL case study.

Table 14. Comparison between traditional and innovative conductors for HV OHLs.

\begin{tabular}{cccccc}
\hline & & Aldrey 185/37 & AAAC-SHC & $\boldsymbol{\Delta}$ & $\boldsymbol{\Delta} \%$ \\
\hline Annual Joule Losses (AJL) & $(\mathrm{GWh})$ & 29.316 & 28.146 & 1.170 & \\
Annual Cost of Losses (ACL) & $(\mathrm{M} €)$ & 1.173 & 1.126 & 0.047 & $-4 \%$ \\
Actualized Annual Cost of Losses (AACL) & $(\mathrm{M} €)$ & 20.122 & 19.318 & 0.804 & \\
\hline
\end{tabular}

As discussed in Section 2, the majority of Italian distribution OHLs is still equipped with copper conductors rather than with aluminium ones. By considering all the replaceable conductors in Table 13, their total extension in the distribution networks (MV and LV) in Italy is about $14 \%$ of the total $191,888 \mathrm{~km}$ (i.e., about 27,000 km). Table 15 reports the results of the cost analysis described in Section 5.1 for all the distribution network conductors considered in the study. Replacing these OHL conductors would lead to a containment of Joule power losses by $28.3 \%$ on a yearly basis ( $1354 \mathrm{GWh}$ ), with a possible cost reduction of about $54 \mathrm{M} €$ (AACL reduction of $929 \mathrm{M} €$ ) and a potential $\mathrm{CO}_{2}$ emission reduction of about $830 \mathrm{kt}$ each year. 
Table 15. Total cost for each traditional conductor in the study and expected benefit using the innovative one.

\begin{tabular}{|c|c|c|c|c|c|c|}
\hline Material & Code & $\begin{array}{c}\text { AJL } \\
\text { (GWh) }\end{array}$ & $\begin{array}{l}\text { ACL } \\
\text { (M€) }\end{array}$ & $\begin{array}{l}\text { AACL } \\
(\mathbf{M} €)\end{array}$ & $\begin{array}{c}\mathrm{CO}_{2} \text { Emissions } \\
\text { Saving (kt) }\end{array}$ & $\begin{array}{c}\text { Joule Losses Potential } \\
\text { Reduction (\%) }\end{array}$ \\
\hline \multirow{2}{*}{ Copper } & $70 / 19$ & 1174.173 & 46.967 & 805.900 & 420.541 & $35.8 \%$ \\
\hline & $95 / 19$ & 1294.695 & 51.797 & 888.600 & 75.191 & $5.8 \%$ \\
\hline \multirow{3}{*}{ Aluminium } & 70/19 & 97.283 & 3.891 & 66.785 & 22.514 & $59.3 \%$ \\
\hline & $95 / 19$ & 106.552 & 4.262 & 73.133 & 18.436 & $44.4 \%$ \\
\hline & $120 / 19$ & 116.131 & 4.645 & 78.708 & 11.282 & $24.9 \%$ \\
\hline \multirow{5}{*}{ Aldrey } & $70 / 19$ & 404.604 & 16.184 & 277.705 & 102.065 & $64.7 \%$ \\
\hline & $95 / 19$ & 23.973 & 0.959 & 16.454 & 4.758 & $50.9 \%$ \\
\hline & $120 / 19$ & 26.112 & 1.044 & 17.922 & 3.544 & $34.8 \%$ \\
\hline & $150 / 37$ & 27.472 & 1.099 & 18.855 & 2.5285 & $23.6 \%$ \\
\hline & $185 / 37$ & 29.316 & 1.173 & 20.122 & 0.457 & $4.0 \%$ \\
\hline \multirow{2}{*}{ ACSR } & $68 / 12+7$ & 217.335 & 8.693 & 149.171 & 50.771 & $59.9 \%$ \\
\hline & $128 / 26+7$ & 1268.931 & 50.757 & 870.948 & 118.127 & $23.9 \%$ \\
\hline \multicolumn{2}{|c|}{ Total } & 4786.577 & 191.471 & 3284.303 & 830.215 & $28.3 \%$ \\
\hline
\end{tabular}

\section{Conclusions}

The current trend in the electricity usage and production and the expected developments in the near future will lead to reinforcements in both the transmission and distribution grids, to reduce the risk of bottlenecks and improve the energy efficiency of the power system. The CALAJOULE project, funded as part of the Italian "Ricerca di Sistema" program, has produced significant results in the development and analysis of new conductors for overhead lines at HV and MV level.

The scope of this paper is to show all the chief findings of the three-year research and chiefly the expected benefits coming from the adoption of such innovative conductors in both transmission and distribution grids, with reference to the presently installed OHL conductors. The paper shows a methodology adopted in the project to evaluate the potential benefits resulting from the usage of the innovative conductors in place of the standard ones. Under some working assumptions (i.e., 40 year OHL lifetime, fixed price of electricity, $\mathrm{CO}_{2}$ emission known, and constant per MWh), the results show a strong, positive impact on the Italian electricity system which could also be replicated, with due distinctions, for other electric grids.

The actualized cost saving for reduced Joule losses in the HV network is estimated in about $37 \mathrm{M€}$, with a corresponding $\mathrm{CO}_{2}$ avoided emission of $847 \mathrm{kt}$ on yearly basis. For the distribution network, by considering a potential reinforcement of the current OHLs with conductors having cross-sections up to $70 \mathrm{~mm}^{2}$, the results have shown an actualized cost reduction of $929 \mathrm{M€}$ with a $\mathrm{CO}_{2}$ emission avoidance of $830 \mathrm{kt}$ per year. It is worth noting that a mere investment cost comparison has not been investigated in this research. However, the investment cost of the distribution novel conductor is comparable with traditional Aldrey one. With regard to the transmission novel conductor, the investment cost is greater than traditional ACSR, but, as demonstrated in the paper, the return on the investment is assured by the savings obtained by less energy losses during the entire OHL lifetime. Hence, the developed prototype is more convenient than a traditional conductor in a long-term perspective.

Author Contributions: Conceptualization, R.B.; Formal analysis, R.B. and S.D.S.; Funding acquisition, R.B.; Investigation, R.B., A.C., C.G., S.D.S., D.M., M.M. and F.P.; Supervision, R.B., R.C. and L.M.; Validation, R.B.; Writing-original draft, M.C.; Writing-review \& editing, R.B., C.G., S.D.S., D.M., M.M. and F.P.

Funding: This research was funded by Ministry of Economic Development in the framework of the Ricerca di Sistema Programme, grant number CCSEB_00176.

Conflicts of Interest: The authors declare no conflict of interest. 


\section{References}

1. Eurostat. Smarter, greener, more inclusive? Indicators to Support the Europe 2020 Strategy; Publications Office of the European Union: Brussels, Belgium, 2018.

2. European Commision. Clean Energy for All Europeans. Available online: https:/ec.europa.eu/energy/en/ topics/energy-strategy-and-energy-union/clean-energy-all-europeans (accessed on 10 November 2018).

3. ENTSO-E. Electricity Balancing in Europe. Available online: https://www.entsoe.eu/news/2018/12/12/ electricity-balancing-in-europe-entso-e-releases-an-overview-of-the-european-electricity-balancingmarket-and-guideline (accessed on 20 November 2018).

4. Bracale, A.; Caldon, R.; Coppo, M.; Canto, D.D.; Langella, R.; Petretto, G.; Pilo, F.; Pisano, G.; Proto, D.; Ruggeri, S.; et al. Active management of distribution networks with the ATLANTIDE models. In Proceedings of the 8th Mediterranean Conference on Power Generation, Transmission, Distribution and Energy Conversion (MEDPOWER 2012), Cagliari, Italy, 1-3 October 2012.

5. Petretto, G.; Cantù, M.; Gigliucci, G.; Pilo, F.; Pisano, G.; Natale, N.; Soma, G.G.; Coppo, M.; Turri, R. Representative Distribution Network Models for Assessing the Role of Active Distribution Systems in Bulk Ancillary Services Markets. In Proceedings of the 19th Power Systems Computation Conference, Genoa, Italy, 20-24 June 2016; pp. 1-7.

6. Kiessling, F.; Nefzger, P.; Nolasco, J.F.; Kaintzyk, U. Overhead Power Lines-Planning, Design, Construction; (Springer, Series: Power Systems); Springer-Verlag Berlin Heidelberg: Heidelberg, Gemany, 2003.

7. Benato, R.; Capra, D.; Conti, R.; Gatto, M.; Lorenzoni, A.; Marazzi, M.; Paris, G.; Sala, F. Methodologies to Assess the Interaction of Network, Environment and Territory in Planning Transmission Lines. In Proceedings of the 2006 CIGRÉ session, Paris, France, 27 August-1 September 2006. Paper C3-208.

8. Benato, R.; Dambone, S.S.; Guglielmi, F. Determination of Steady-State and Faulty Regimes of Overhead Lines by Means of Multiconductor Cell Analysis (MCA). Energies 2012, 5, 2771-2793. [CrossRef]

9. Usman, M.; Coppo, M.; Bignucolo, F.; Turri, R.; Cerretti, A. Multi-Phase Losses Allocation Method for Active Distribution Networks based on Branch Current Decomposition. IEEE Trans. Power Syst. 2019. [CrossRef]

10. Cerretti, A.; Di Lembo, G.; Valtorta, G. Improvement in the continuity of supply due to a large introduction of Petersen coils in HV/MV substations. In Proceedings of the CIRED 2005-18th International Conference and Exhibition on Electricity Distribution, Turin, Italy, 6-9 June 2005.

11. Benato, R.; Dambone, S.S.; Poli, M.; Quaciari, C.; Rinzo, G. An On-Line Travelling Wave Fault Location Method for Unearthed-Operated High Voltage Overhead Line Grids. IEEE Trans. Power Deliv. 2018, 33, 2776-2785. [CrossRef]

12. Benato, R.; Caldon, R.; Coppo, M.; Dambone, S.S.; Mimo, D.; Peroni, D.; Previatello, M. Highly Efficient Overhead Line Innovative Conductors with Reduced Joule Power Losses. In Proceedings of the 2017 AEIT International Annual Conference, Cagliari, Italy, 20-22 September 2017.

13. Benato, R.; Caldon, R.; Coppo, M.; Dambone, S.S.; Rinzo, G.; Mimo, D. Evaluation of Joule Power Losses Reduction in Overhead Lines with Innovative Conductors. In Proceedings of the 2018 AEIT International Annual Conference, Bari, Italy, 3-5 October 2018.

14. Benato, R.; Paolucci, A. EHV AC Undergrounding Electrical Power. Performance and Planning; (Springer, Series: Power Systems); Springer-Verlag London: London, UK, 2010; Volume 47.

15. Benato, R.; Napolitano, D. Overall Cost Comparison Between Cable and Overhead Lines Including the Costs for Repair After Random Failures. IEEE Trans. Power Deliv. 2012, 27, 1213-1222. [CrossRef]

16. Benato, R.; Dambone, S.S.; Guglielmi, F.; Partal, E.; Tleis, N. Zero Sequence Behaviour of a Double-Circuit Overhead Line. In Proceedings of the 2014 IEEE PES T\&D Conference and Exposition, Chicago, IL, USA, 14-17 April 2014.

17. Benato, R.; Dambone, S.S.; Guglielmi, F.; Partal, E.; Tleis, N. Ground Return Current Behaviour in High Voltage Alternating Current Insulated Cables. Energies 2014, 7, 8116-8131. [CrossRef]

18. Benato, R.; Colla, L.; Dambone, S.S.; Marelli, M. Review of High Current Rating Insulated Cable Solutions. Electr. Power Syst. Res. 2016, 133, 36-41. [CrossRef]

19. Benato, R.; Dambone, S.S.; Guizzo, L.; Rebolini, M. The Synergy of the Future: High Voltage Insulated Power Cables and Railway-Highway Infrastructures. IET Gener. Transm. Distrib. 2017, 11, 2712-2720. [CrossRef]

20. Benato, R.; Dambone, S.S. A New Multiconductor Cell Three-Dimension Matrix-Based Analysis Applied to a Three-Core Armoured Cable. IEEE Trans. Power Deliv. 2018, 33, 1636-1646. [CrossRef] 
21. Zecchino, A.; Hu, J.; Coppo, M.; Marinelli, M. Experimental Testing and Model Validation of A Decoupled-Phase on-Load Tap-Changer Transformer in An Active network. IET Gener.Transm. Distrib. 2016, 10, 3834-3843. [CrossRef]

22. Cigré Technical brochure $\mathrm{n}^{\circ}$. Alternating Current (ac) Resistance of Helically Stranded Conductors. Ecigre, Posted 2008. Available online: https://nanopdf.com/download/alternating-current-ac-resistance-of-helically_pdf (accessed on 27 June 2009).

23. Cigré Technical brochure ${ }^{\circ}$. Guide for Qualifying High Temperature Conductors for Use on Overhead Transmission Lines. Ecigre, Posted 2010. Available online: https://e-cigre.org/publication/426-guide-for-qualifying-hightemperature-conductors-for-use-on-overhead-transmission-lines (accessed on 10 October 2011).

24. Cigré Technical brochure $n^{\circ}$. Conductors for the Uprating of Overhead Lines. Ecigre, Posted 2004. Available online: https://e-cigre.org/publication/244-conductors-for-the-uprating-of-overhead-lines (accessed on 18 April 2006).

25. Landwehr, G.; Marais, P. Practical Comparison of Power line Upgrading and Upgrading Result. Cigré Sci. Eng. 2016, 5. (ISSN 1286-1146).

26. IEEE. 738-1993-IEEE Standard for Calculating the Current-Temperature Relationship of Bare Overhead Conductors; IEEE: Piscataway, NJ, USA, 1993.

27. EPRI. Demonstration of Advanced Conductors for Overhead Transmission Lines; Final Project Report; EPRI: Palo Alto, CA, USA, July 2008.

28. Kumar, B.G.; Singh, R.P.; Nakamura, T. Degradation of Carbon Fiber-Reinforced Epoxy Composites by Ultraviolet Radiation and Condensation. J. Compos. Mater. 2012, 36, 2713-2733. [CrossRef]

29. Fink, J.K. High Performance Polymers, 1st ed.; William Andrew: Norwich, NY, USA, 2008.

30. Wright, D. Failure of Plastics and Rubber Products: Causes, Effects and Case Studies Involving Degradation; Smithers Rapra Press: Akron, OH, USA, 2001.

31. CEI STANDARD 11-60. Portata al limite termico delle line elettriche aeree esterne con tensione maggiore di $100 \mathrm{kV}$; CEI: Trieste, Italy, 2002.

32. ENEL; Rapporto Ambientale, 2013. Available online: https://www.enel.com/content/dam/enel-com/governance pdf/reports/bilanci-annuali/2013/Enel_Rapporto_Ambientale_2013.pdf (accessed on 1 February 2014).

33. Schurig, O.R.; Frick, C.U. Heating and Current Carrying Capacity of Bare Conductor for Outdoor Service. Gen. Electr. Rev. 1930, 33, 141-157. 